\title{
Beyond "Bad News": The Diagnosis, Prognosis and Classification of Lymphomas and Lymphoma Patients in the Age of Biomedicine (1945-1995)
}

\author{
PETER KEATING and ALBERTO CAMBROSIO*
}

\section{Prognosis and the Development of Clinical, Pathological and Biological Classifications}

Historians have long recognized that medical prognosis, along with diagnosis and treatment, constitute the backbone of clinical medicine. ${ }^{1}$ They have observed, for example, that even in the depths of late-nineteenth-century therapeutic nihilism, physicians did not hesitate to prognosticate. ${ }^{2}$ Medical sociologists have recently identified an increasing demand for prognostic information and a heightened interest in its practice. $\mathrm{N}$ A Christakis has singled out the growing prevalence of chronic disease, and new forms of medical technology, including those associated with reproduction and the new genetics, as well as efforts directed towards cost containment as causes of this renewed interest and demand. Confronted with this demand, clinicians have sometimes hesitated before pronouncing on the future. ${ }^{3}$ Philosophers have suggested that part of the clinicians' reluctance to predict lies in the fact that modern prognostic information comes from statistics about classes or groups of patients and so does not apply directly to individuals. ${ }^{4}$ The problem of prognosis is further

\begin{abstract}
* Peter Keating, $\mathrm{PhD}$, Department of History, Université du Québec à Montréal, Montréal, P.Q., Canada; Alberto Cambrosio, PhD, Social Studies of Medicine, McGill University, Montréal, Canada; and INSERM, Unité 379, Marseille, France.
\end{abstract}

The authors would like to thank the Burroughs Wellcome Fund, the National Humanities Center and the Fonds pour la formation des chercheurs et l'aide à la recherche (FCAR-Québec), for their support in the production of this article. We would also like to thank Victoria Harden at the NIH, Judy Grosberg at the NCI and Mike Rhode at the Armed Forces Institute of Pathology for their help in the archives of their respective institutions.

\footnotetext{
${ }^{1}$ Indeed, nineteenth-century historians of medicine felt that prognosis constituted the singular achievement of ancient medicine. See for a revision of this view, Ludwig Edelstein, 'Hippocratic Prognosis', in idem, Ancient medicine, eds. O Temkin and C L Temkin, Baltimore, Johns Hopkins University Press, 1967, pp. 65-85. For a brief overview of the history of prognosis, see Jean-Charles Sournia, 'D'Hippocrate à la médecine prédictive: histoire du prognostic', Asklepios, 1996, 10: 26-9.

${ }^{2}$ On therapeutic nihilism, see Erna Lesky, The Vienna medical school of the 19th century, transl.
}

L Williams and L S Levij, Baltimore, Johns Hopkins University Press, 1976.

${ }^{3} \mathrm{~N}$ A Christakis and G A Sachs, 'The role of prognosis in clinical decision making', J. Gen. Intern. Med., 1996, 11: 422-5; N A Christakis, 'The ellipsis of prognosis in modern medical thought', Soc. Sci.Med., 1997, 44: 301-15; and N A Christakis, Death foretold: prophecy and prognosis in medical care, University of Chicago Press, 1999.

${ }^{4} \mathrm{~J}$ Hilden and Dik F Habbema, 'Prognosis in medicine: an analysis of its meaning and roles', Theor. Med., 1987, 8: 349-65, p. 350; Claudia Weisemann, 'The significance of prognosis for a theory of medical practice', Theor. Med. Bioeth., 1988, 19: 253-61, p. 254. Paul has labelled the problem of applying statistical knowledge to individual cases a "theoretical hiatus" for clinical medicine. See Norbert Paul, 'Incurable suffering from the "hiatus theoreticus"? Some epistemological problems in modern medicine and the clinical relevance of philosophy of medicine', Theor.Med.Bioeth., 1998, 19: 229-51. Philosophers of clinical medicine also tell us, somewhat implausibly, that "[a] prognosis is a prediction of what the future stage of disease will be, regarding a single case and it is not an inherent characteristic of the patient or an innate part of the (so-called) natural history of the disease"; Dominick A Rizzi, 'Medical prognosis: some fundamentals', Theor. Med., 1993, 14: 365-75, p. 368. 


\section{Peter Keating and Alberto Cambrosio}

compounded by the fact that even when an individual prognosis is made, it cannot, except by definition, be easily detached from the biology of the individual or the natural history of disease. Indeed, practitioners readily admit that " $[t]$ he two fundamental processes in medicine, those of diagnosis and prognosis, are confused at times". 5 As can be easily imagined, any diagnosis produces some kind of prognosis if only that of "future uncertain".

The intertwining of diagnosis and prognosis can be explored in many ways. No matter how this is done, however, it must be admitted that the post-war rise of that novel epistemological, social and institutional fusion of biology and pathology known as biomedicine provides the context within which these evolving relations must first be examined. ${ }^{6}$ In this paper we explore the evolution of relationships between clinical or prognostic classifications and those (mainly diagnostic) developed in adjacent areas of biomedicine such as pathology and histology. We focus in particular on the continuing attempts since the Second World War to relate clinical research findings to biological and pathological findings and to develop standards that allow clinical researchers to compare across clinical trials. Despite constant pressure from both biology and pathology to align classifications with these external, and therefore, more "objective" standards, clinical research has attempted to maintain its own criteria of relevance and success in the constant revision of its norms and forms. None the less, clinical classifications have become increasingly based on biological and pathological findings. Indeed, partly due to the increasing role played by multi-centre, co-operative clinical trials in modern cancer therapy, independent "prognostic" classifications have emerged to organize, collate and standardize forms of information formerly contained within diagnostic categories.

Such tensions may seem obvious from a pragmatic point of view. In addition to connecting individual patients to larger biological and pathological categories, clinical classifications that "stage" tumours according to their anatomic extent or spread, or that "grade" tumours according to their aggressivity depending upon their histological appearance at biopsy, determine therapeutic choices. In this sense, the purpose of clinical classifications clearly goes beyond the mere articulation of the "art" of therapy with the more fundamental "scientific" categories of pathology and biology. It is equally obvious, however, that an efficient and useful staging system is not necessarily very enlightening with regards to the pathological mechanisms underlying the emergence and spread of the disease in question. Similarly, the classification of diseases according to their histopathology may not be the most adequate reflection of the molecular-biological entities at play in the process. Finally, ordering pathological entities according to their biological substratum or constituents may contribute little to their immediate clinical management. In short, there are a number of problems attendant upon the articulation and confrontation of the various kinds of classifications.

As an illustration of these remarks, we have chosen to examine the evolution of clinical and histopathological classifications of the lymphomas. This category includes two distinct yet related classes of disease: Hodgkin's disease and the non-Hodgkin's lymphomas. These two classes allow us to develop a comparison and show that, for example, whereas clinical staging emerged ahead of and in some respects outside of biological and pathological

${ }^{5}$ Mary Gospodarowicz et al., 'Prognostic factors in clinical decision making: the future', Cancer, 2001,91: 1688-95, p. 1688.
${ }^{6}$ For a description of biomedicine and its specific epistemic and institutional contours, see Peter Keating and Alberto Cambrosio, 'Biomedical platforms', Configurations, 2000, 8: 337-87. 


\section{Diagnosis, Prognosis and Classification of Lymphomas}

theories of the spread of the disease in the case of Hodgkin's disease, attempts to develop a similar staging system for the lymphomas were not so successful. Given that work continues within this enterprise, our remarks should be considered more exploratory than definitive. We can none the less state at the outset that it is not so much that diagnosis and prognosis are confused, as that: (1) many classifications of the same entity or person are possible depending upon the purpose of the classification, and (2) a single classification may contain both diagnostic and prognostic dimensions. In other words, it seems that classifications respond to multiple agendas. ${ }^{7}$

Consider, for example, the following case of an individual diagnosed with nonHodgkin's lymphoma (NHL):

I was diagnosed April 1, 1996. I had a swollen neck gland and the back of my tongue had a huge hump on it. The ear, nose and throat doctor took a piece off the back of my tongue, sent me over for $\mathrm{X}$-rays and a CT scan (both negative by the way). I went back to the ENT doctor in two days and he gave me the bad news: large B-cell NHL, diffuse. I then went to an oncologist friend who I had known for twenty-five years, though not professionally. He did bone marrow studies, a spinal fluid analysis, more CT scans, all kinds of blood work and put me to sleep for a gastroenterology looksee ... all negative, so he staged it IIA, high grade. ... After seven CHOP [chemotherapeutic] treatments, I had radiation to the neck area every day for four weeks. I was left with very painful yet numb feet, and tingling in my left arm, which is still there. ${ }^{8}$

This initial diagnosis contained, in spite of its neutral presentation as a scientific observation, a form of prognosis, which the patient termed "bad news". As we will see, specification of the lymphoma as "large B-cell NHL, diffuse" already says a lot about what is expected to happen to the patient and what is expected to happen to the disease. Secondly, when such a category of disease is "staged" as in "IIA, high grade", more than prognosis-for these are indeed prognostic terms-is at stake. In order to reach such a conclusion, clinicians and laboratory investigators necessarily undertook an exploration of the biology of the entity in question-described, for example, its targets and its spread-thus further specifying the diagnosis. As in the world of Laplacian physics, a complete diagnosis would result in an exact prognosis just as an exact prognosis would presuppose a complete diagnosis.

In what follows, our discussion will include both Hodgkin's disease and non-Hodgkin's lymphomas in recognition of the fact that there has been a continual evolution in the relation between the lymphomas and the disease first described by Thomas Hodgkin in 1832. Although the name "non-Hodgkin's lymphomas" seems to suggest that Hodgkin's disease is a lymphoma, the two have been treated both clinically and pathologically quite separately since the end of the Second World War. Their divergent evolution allows us the opportunity to make a number of comparative remarks concerning the complex relations that exist between prognostic and diagnostic classifications, and the manifold ways in which biomedical innovation may transform these relations.

Since the beginning of the twentieth century, Hodgkin's disease has been defined as a discrete histopathological entity on the basis of the presence of a giant cell known as the Reed-Sternberg cell. The histopathological distinctiveness of Hodgkin's disease escaped

\footnotetext{
${ }^{7}$ See Geoffrey C Bowker and Susan Leigh Star, Sorting things out: classification and its consequences, Cambridge, MA, MIT Press, 1999, esp. 'Part One: Classification and large scale infrastructures'.
}

\footnotetext{
${ }^{8}$ Lorraine Johnston, Non-Hodgkin's lymphomas: making sense of diagnosis, treatment and options, Sebastopol, CA, O'Reilly, 1999, p. 132.
} 


\section{Peter Keating and Alberto Cambrosio}

Hodgkin himself, who worked without a microscope. Indeed, subsequent reviews of Hodgkin's original seven biopsy specimens have shown that only two would today be diagnosed histologically as Hodgkin's disease, the others falling under the category of non-Hodgkin's lymphomas (NHLs) or, the great confounder of the nineteenth century, tuberculosis. ${ }^{9}$ In recent times, however, this histopathological distinction has faded. The redefinition of the Reed-Sternberg cells as (in most cases) B cells has effectively broken down the histological barrier between Hodgkin's disease and the non-Hodgkin's lymphomas and has brought the two together in the latest histopathological classification of the lymphomas (the REAL [Revised European-American Lymphoma] classification). None the less, partly in recognition of its clinical specificity, and partly because of professional and institutional inertia, the term Hodgkin's disease is still widely used even though, as some pathologists argue, Hodgkin's disease should be called Hodgkin's lymphoma. ${ }^{10}$

The present histopathological unity is, however, of recent origin. There have been longstanding and persistent differences in the clinical classifications used to manage Hodgkin's and NHL patients. Before turning to these differences, let us first note that there has been an evolution in the kinds of clinical classifications used in the field of cancer in general that corresponds to the rise of post-war clinical research. The first and oldest classifications were based on the clinical descriptions of disease that had accumulated since the eighteenth century and that correlated anatomic and clinical findings in the form of clinical "pictures". ${ }^{11}$ The "pictures" offered not only a symptomology of the disease and a semiotics for its diagnosis, but, in describing the natural history or course of the disease, provided a prognosis that was generally rather bleak. Since the end of the Second World War and the advent of large-scale chemotherapy, various schemes that determine predictive stages in a disease's progress and prognostic indices (composed of a variety of biological and pathological indicators) have replaced the original clinical pictures as sources of prognostic information. Moreover, given that cancer now rarely goes untreated, clinicians often prefer

\footnotetext{
${ }^{9}$ See R N Poston, 'A new look at the original cases of Hodgkin's disease', Cancer Treat. Rev., 1999, 25: 151-5. For previous reviews, see H Fox, 'Remarks on the presentation of microscopical preparations made from some of the original tissue described by Thomas Hodgkin, 1832', Ann. Med. Hist., 1926, 8: 370-4; W St C Symmers, 'The lymphoreticular system', in W St C Symmers (ed.), Systemic pathology, vol. 2, Edinburgh, Churchill \& Livingstone, 1978, pp. 504-892; K Lennert, 'Die Beziehungen von Hodgkinund non-Hodgkin-Lymphomen', Arzneim-Forsch./ Drug Res., 1987, 37: 255-9.

${ }^{10} \mathrm{~A}$ committee of experts, many of whom had been involved in the formulation of the $1994 \mathrm{REAL}$ classification, working for the WHO recently failed to reach a conclusion on this score. Pathologists on the committee felt that the term Hodgkin's disease should be abandoned in favour of Hodgkin's lymphoma. Other members of the committee felt the change "unnecessary". See N L Harris et al., 'The World Health Organization classification of neoplastic diseases of the hematopoietic and lymphoid tissues. Report of the Clinical Advisory Committee, Airlie
}

House, Virginia, November, 1997', Ann. Oncol, 1999, 10: $1419-32$, p. 1430. For the evolving relations between Hodgkin's and non-Hodgkin's lymphomas, see N L Harris, 'The many faces of Hodgkin's disease around the world: what have we learned from its pathology?', Ann. Oncol., Supplement, 1998, 9: S45-S56; Karl Lennert, 'Borderlands of pathological entities', in Ian T Magrath (ed.), The non-Hodgkin's lymphomas, 2nd ed., New York, Oxford University Press, 1997, pp. 133-67, esp. 133-7; Elaine S Jaffe and Konrad Mueller-Hermelink, 'Relationship between Hodgkin's disease and non-Hodgkin's lymphomas', in P M Mauch et al. (eds), Hodgkin's disease, Philadelphia, Lippincott, Williams and Wilkins 1999, pp. 181-93.

${ }_{11}$ Beginning with Sydenham (among others), see Knud Faber, Nosography in modern internal medicine, New York, Paul B Hoeber, 1923, and Owsei Temkin, 'The scientific approach to disease: specific entity and individual sickness', in A C Crombie (ed.), Scientific change, London, Heinemann Educational, 1963 , pp. 629-47. In the seventeenth century and the revival of clinical description, the anatomo-clinical 


\section{Diagnosis, Prognosis and Classification of Lymphomas}

the term "treated history" over "natural history". ${ }^{12}$ Prognosis, in other words, has been separated from diagnosis even though, as previously noted, knowledge of one generally entails knowledge of the other.

The most widespread of the aforementioned staging schemes in the field of cancer is the TNM (tumour, node, metastasis) system. Although, for anatomical reasons, the TNM system cannot be used to stage lymphomas, its extra-clinical origin does bear mention. Not originally intended to direct treatment management, the TNM system grew out of French wartime efforts to develop a nomenclature for a public health enterprise known as the Permanent Cancer Survey. Organized by the National Hygiene Institute, the Survey set out in 1943 to create a cancer register, including all cases of the disease treated in cancer centres. Initial results showed, however, that uniform categorization of the cancers was consistently compromised by the fact that the same "histological" cancer could be registered under a variety of names depending upon the anatomical extent of the disease. To overcome the proliferation of entities based on anatomical extent, Pierre Denoix, director of the project, proposed standardization in reporting of the latter. ${ }^{13}$ Denoix developed this standardized system throughout the 1950s, at the end of which it was adopted by the International Union Against Cancer for tumours of the breast and larynx, and then became an international standard. ${ }^{14}$

While the clinical classification of the lymphomas participated in this overall evolution from picture to stages, it did so in its own way. By the time the TNM system had been widely adopted in the 1960s, clinical researchers had already developed staging schemes and clinical classifications for the lymphomas. It is to these that we now turn.

\section{The Diagnosis and Prognosis of Hodgkin's Disease}

Pathological and clinical classifications, although overlapping, were indeed distinct. In order to understand the contrast between the two kinds of classification, we begin with the classifications developed by pathologists for Hodgkin's disease. In the immediate post-war period, three types of Hodgkin's based on the cellular appearances in stained tissue samples were recognized. ${ }^{15}$ These were not hard and fast distinctions: in an extended series of biopsies conducted at the US Army Institute of Pathology, R Philip Custer and William G Bernhard noted that less than 25 per cent of cases fell into a single histopathological category, indicating considerable fluidity between the three types. ${ }^{16}$ Custer and Bernhard concluded that not only were divisions within the diagnosis of Hodgkin's artificial, but that

method is often said to have been perfected in earlynineteenth-century Paris. See Caroline Hannaway and Ann La Berge (eds) Constructing Paris medicine, Amsterdam and Atlanta, Rodopi Editions, 1998.

${ }^{12}$ See for example, Gospodarowicz et al., op. cit., note 5 above, p. 1691.

${ }^{13}$ See Marie Ménoret, 'The genesis of the notion of stages in oncology: the French permanent cancer survey (1943-1952)', Soc. Hist. Med., 2002, 15: 291-302.

${ }^{14}$ UICC Committee on Clinical Stage Classification and Applied Statistics, Clinical stage classification and presentation of results, malignant tumors of the breast and larynx,
Paris, International Union Against Cancer, 1958.

See in general, Leslie H Sobin, 'TNM: principles, history, and relation to other prognostic factors', Cancer, Supplement, 2001, 91: 1589-92.

${ }^{15}$ These are the divisions presented by $\mathrm{H}$ Jackson and F Parker, Hodgkin's disease and allied disorders, New York, Oxford University Press, 1947.

${ }^{16} \mathrm{R}$ Philip Custer and William G Bernhard, 'The interrelationship of Hodgkin's disease and other lymphatic tumors', Am. J. Med. Sci., 1948, 216: 625-42, p. 633. 


\section{Peter Keating and Alberto Cambrosio}

the lymphomas as a whole blended into each other to such a degree that "a rigid subclassification of lymphatic tumours is artificial and confusing". ${ }^{17}$

In the first decade of the twentieth century, clinicians had also sub-categorized Hodgkin's into a series of clinical pictures. ${ }^{18}$ By the eve of the Second World War, further clinical work had subdivided these "pictures" according to several courses of evolution. Following the French specialists, Paul Chevalier and Jean Bernard, the Swiss radiotherapist René Gilbert had delineated four varieties of evolution. ${ }^{19}$ Their diagnosis demanded considerable clinical acumen for they were combined with a further eleven different lymphatic and extralymphatic forms. Experts in radiotherapy such as Gilbert ${ }^{20}$ believed that these clinical variants precluded any possible standardization of treatment. When combined together with the problem of shifting histopathology, Gilbert, unsurprisingly, had this to say about standardization just before the outbreak of the Second World War:

By its polymorphism and by the great variation in its evolutionary features in different cases ... the disease presents great diagnostic and therapeutic difficulties. Its treatment cannot be standardized; it must always be adapted to each particular case and, on the part of the treating physician, requires much clinical sense. ${ }^{21}$

None the less, standardization is precisely what happened in the post-war period.

Lloyd F Craver, physician at the Sloan-Kettering Memorial Hospital in New York and one of the administrators of the first cancer chemotherapy trials conducted with nitrogen mustard just after the war, took the first step in the standardization process. For clinical trial purposes, he organized the multiple clinical pictures into three classes of disease: (I) localized; (II) regional (above or below the diaphragm); and (III) generalized, the latter having been singled out for nitrogen mustard therapy. ${ }^{22}$ To go from classes to stages, however, required a further step. In a series of papers published in the 1950s and now regarded as "classics", ${ }^{23}$ Vera Peters at the Toronto General Hospital subtly transformed

${ }^{17}$ Ibid., p. 641.

${ }^{18}$ See for example, Kurt Ziegler, Die Hodgkinsche Krankheit, Jena, G Fischer, 1911. Karnofsky has analysed the relationship between these pictures and present-day stages in David A Karnofsky, 'The staging of Hodgkin's disease', Cancer Res., 1966, 26: 1090-4, pp. 1090-1.

${ }^{19}$ See René Gilbert, 'Radiotherapy in Hodgkin's disease (Malignant Granulomatosis): Anatomic and clinical foundations; governing principles; results', Am. J. Roentgenol. \& Rad. Therapy, 1939, 41: 198-241, p. 204. The Chevalier and Bernard classification of the forms of evolution can be found in P Chevalier and J Bernard, La maladie de Hodgkin (lymphogranulomatose maligne), Paris, Masson, 1932.

${ }^{20}$ Gilbert is generally credited with having put radiotherapy of Hodgkin's disease on the map in the inter-war period. Henry Kaplan, for example, credited Gilbert with having invented enlarged field radiation techniques; viz. irradiation of the entire lymph node chain rather than the specific area of involvement. As Gilbert did use control, post-war radiotherapists imbued with the notion of a clinical trial had "a tendency to dismiss his apparently superior results as being due to case selection". Henry S Kaplan, "The radical radiotherapy of regionally localized Hodgkin's disease', Radiology, 1962, 78: 553-61, p. 553. See also, Maurice Tubiana, 'Development of the concept of Hodgkin's disease as a curable illness: the European experience', in Mauch et al. (eds), op. cit., note 10 above, pp. 23-4.

${ }^{21}$ Gilbert, op. cit., note 19 above, p. 198.

${ }^{22}$ Lloyd F Craver, 'Recent advances in treatment of lymphomas, leukemias and allied disorders: the Bulkley lecture', Bull. N. Y. Acad. Med., 1948, 24: 3-25, p. 12. See also, D P Slaughter and L F Craver, 'Hodgkin's disease; five year survival rate; value of early treatment; notes on four cases of long duration', Am. J. Roentgenol. Rad. Therapy, 1942, 47: 596-606. This, in turn, was an expansion of Dorothy Reed's 1902 stages (Stage I: lymph node enlargement, Stage II, progressive cachexia). D M Reed, 'On pathological changes in Hodgkin's disease with especial reference to its relation to tuberculosis', Johns Hopkins Hosp. Rep., 1902, 10: 133-96.

${ }^{23}$ Saul A Rosenberg, 'Development of the concept of Hodgkin's disease as a curable illness: the American experience', in Mauch et al. (eds), op. cit., note 10 above, pp. 47-57, on p. 47. 


\section{Diagnosis, Prognosis and Classification of Lymphomas}

Craver's classes ${ }^{24}$ by evaluating her population of patients treated at the Toronto General in terms of the factors that correlated with five- and ten-year survival rates. The most significant prognostic factors turned out to be extent of anatomical involvement upon presentation of disease or, in other words, Craver's classes. Unlike the latter, however, Peters' articulation of the classes with survival data enabled her to specify three stages based not only on presentation of the anatomic extent of disease, but also on response to treatment. For example, Peters defined stage one as more than "involvement of only one lymph node region or a single lesion elsewhere, with no constitutional symptoms"; indeed, she went on to show that the five-year survival rate following radiotherapy was approximately 88 per cent. Unlike the classes, then, the stages were correlated with treatment history and could thus be construed as "truly" prognostic.

The stages thus overlapped with but were not identical to the clinical pictures or classes. In particular, Peters went on in the same paper to use the stages in a comparison of two forms of irradiation therapy; one with and one without prophylactic radiation. In other words, Peters made uniform therapy possible-impossible, we recall, according to Gilbert-by dividing the disease into stages and putting patients into the stages rather than drawing increasingly complicated "forms" in an attempt to gather patients into a complex series of "pictures". 25 More than a description, stages set out prescriptions or rules for therapeutic intervention.

An additional consequence of Peter's scheme was that, by reporting treatment results in terms of clinical classification, she described the evolution of the disease under specific therapeutic regimes; a "treatment history" as opposed to a "natural history". Peters' approach not only constituted a decisive step in the standardization of treatment but also overcame the initial obstacle to that standardization, the cloudy picture presented by the somewhat fluid pathology. Peters' scheme also showed the "clinical" classification to be superior to the "pathological" classification in terms of prognosis. In particular, she concluded as a result of her findings that "the pathological picture is a very necessary, indeed the only proof of the diagnosis, but in establishing the prognosis it acts as a valuable aid, but is not as conclusive as the clinical factors". ${ }^{26}$ Robert Lukes, who in 1954 had become head of the Lymphatic Tumor Division at the US Armed Forces Institute of Pathology, recognized this novelty in Peters' method when, reviewing previous histopathological classifications in the early 1960s, he wrote:

The application of a clinical staging method by Peters to survival studies in Hodgkin's disease and in the evaluation of the effectiveness of radiation therapy without regard to histologic classification presented a new analytic approach. ${ }^{27}$

\footnotetext{
${ }^{24}$ See M Vera Peters, 'A study of survivals in Hodgkin's disease treated radiologically', Am.J. Roentgenol., 1950, 63: 299-311; M Vera Peters and K C H Middlemiss, 'A study of Hodgkin's disease treated by irradiation', Am. J. Roentgenol., 1958, 79: 114-21.

${ }^{25}$ As Gianni Bonadonna has noted in a recent appreciation of Peters' work, the latter went beyond the clinical simplification and improved treatment: "Important from many points of view were the initial publications by Peters, who, with Gordon Richards, between 1928 to 1953 , used a treatment plan very similar to that of Gilbert. First, she reported treatment
}

results according to a three-stage clinical classification that also included the presence or absence of systemic symptoms. By doing this, she started a new era of rational emphasis on diagnostic evaluation and treatment reporting based on the anatomic extent of involvement." Gianni Bonadonna, 'Historical review of Hodgkin's disease, Br. J. Haematol., 2000, 110: $504-11$, on p. 10 out of 16 from download.

${ }^{26}$ Peters, op. cit., note 24 above, p. 307.

${ }^{27}$ Robert J Lukes, 'Relationship of histologic features to clinical stages in Hodgkin's disease', Am.J. Roentgenol., 1963, 90: 944-55, p. 944. 


\section{Peter Keating and Alberto Cambrosio}

Indeed, inverting the pathology-clinic hierarchy, Lukes went on to use Peters' stages to evaluate clinically the histopathological classification "established on the basis of the author's [Lukes'] experience with over 3,000 cases of Hodgkin's disease while Chief of the Hematopathology Section of the Armed Forces Institute of Pathology from 1954$1962 "{ }^{28}$ Lukes' comparison showed his histological types to be distinctly superior to previous pathological classifications in so far as, when correlated with the clinical stages, they dissipated much of the fluidity that had been associated with the histopathological subtypes. ${ }^{29}$

In addition to the advances in radiotherapy, the role of chemotherapy was considerably enhanced during Lukes' tenure at the US Armed Forces Institute of Pathology. Initial experiments with nitrogen mustard carried out in the late 1940s by researchers like Craver at Sloan-Kettering were greatly expanded in 1955 with the formation of the co-operative clinical trials groups organized by the National Cancer Institute (NCI) to conduct largescale, multi-institutional stage two and stage three clinical trials. The programme grew exponentially for the first ten years, recruiting 1,000 clinicians and 16,000 patients in over 250 institutions in the largest clinical cancer trials ever seen. ${ }^{30}$ Promising results with the leukaemias and the lymphomas had led C Gordon Zubrod, the head of the programme at the NCI, to create a series of task forces in 1963 specifically targeting the leukaemias and the lymphomas.

The development of clinical trials abroad, and the emerging variability in the application of staging criteria in Hodgkin's disease, suggested the need for a standard international classification system. Thus Peters' staging system and Lukes' new histopathological subtypes were showcased at two international symposia on Hodgkin's disease held in 1965, one in Paris ${ }^{31}$ and one in Rye, New York. At the Paris meeting, Lukes' system shone through in a negative manner when an international panel of three pathologists, including Lukes, reported the results of a blind examination of 395 biopsies from six different hospitals. The experts concluded that, although the criteria for the diagnosis of Hodgkin's were more or less internationally equivalent, competing sub-classifications added little in terms of prognostic information and that, in this respect, Lukes' system would be preferable as an international standard. ${ }^{32}$

The proposals presented in Paris in February were resubmitted to the Rye symposium in September 1965. Here, an international committee proposed the adoption of a slightly modified version of Peters' system subsequently known as the Rye classification. ${ }^{33}$

\footnotetext{
${ }^{28}$ Ibid., p. 947.

${ }^{29}$ Ibid., p. 955 . Lukes compared his own classification explicitly with that developed by Jackson and Parker, op. cit., note 15 above.

${ }^{30}$ These numbers concern the 22 co-operative groups active in 1968 who were then conducting over 230 different studies. See 'Recommendations of the cancer clinical investigation review committee and the national advisory cancer council regarding the cooperative clinical cancer research program', National Cancer Institute, March 1968, p. 1.

${ }^{31}$ For the conference report, see Maurice Tubiana, 'La radiothérapie de la maladie de Hodgkin: Symposium international organisé à Paris le 15 février 1965', Nouv. Rev. Fr. Hematol., 1966, 6: 6-120.
}

\footnotetext{
${ }^{32}$ Robert J Lukes, C Gompel, and C Nezelof, 'Le diagnostique histopathologique de la maladie de Hodgkin. Analyse préliminaire d'une étude conduite à l'aveugle sur 395 observations par trois pathologistes de nationalité différente', Nouv. Rev. Fr. Hematol., 1966, 6: 11-15, p. 14. Lukes presented his system using 377 cases from the Armed Forces Institute of Pathology Collection. See R J Lukes, J Butler, and Ethel B Hicks, 'Le pronostic de la maladie de Hodgkin d'après la variété histologique et le stade clinique', Nouv. Rev. Fr. Hematol., 1966, 6: 15-22.

${ }^{33}$ The modification consisted of the addition of a stage four proposed by Kaplan in 1963. The stages were further sub-coded "A" (asymptomatic) or "B" (symptomatic: fever, night sweats and itching). The
} 


\section{Diagnosis, Prognosis and Classification of Lymphomas}

Although it continued the themes at the Paris conference, the Rye symposium also occurred within a framework of conferences that had been set up by the American Cancer Society (ACS) in 1963, with additional financial support by the National Cancer Institute. The planning committee consisted of members of the two task forces-the Acute Leukemia Task Force and the Lymphoma Task Force-that had recently been organized by the NCI. ${ }^{34}$ In addition to the endorsement of Peters' staging system by the "Classification Committee", the Nomenclature Committee also adopted Lukes' histopathological classification of Hodgkin's disease. The latter had been further bolstered by interim studies mobilizing the considerable clinical material at Lukes' disposal, namely data collected during a fifteento eighteen-year follow-up study of 377 US Army cases from the Second World War. ${ }^{35}$ More than a simple correlation, Lukes' studies showed that the pathologic classification and the clinical classification could not, in fact, be sharply distinguished. Both were related to a third variable, the host response to disease. Rather than an independent variable, the clinical stage was, according to Lukes, a reflection of a combination of host response and histologic type. ${ }^{36}$ The two classifications-clinical and pathological-thus became intertwined and the detection of the histological class alone later became known as "pathological staging". 37

There were, however, some hesitations that bear mention, as they illustrate some of the initial confusion surrounding this alliance of prognosis and pathology. In particular, given that Lukes had constructed his histopathological types partly on the basis of prognostic criteria, some Rye conference participants suspected that Lukes had not uncovered distinct types of Hodgkin's disease but simply different phases of the same bio-pathological process. In the course of conference discussions, some researchers suggested that the

committee consisted of Maurice Tubiana (Villejuif, France); Eric Easson (Manchester, UK), Lillian Fuller (Houston, USA), David Karnofsky (New York, USA), Robert Lukes (Los Angeles, USA), Saul Rosenberg (Palo Alto, USA) and Vera Peters (Toronto, Canada). See Saul A Rosenberg, 'Report of the committee on the staging of Hodgkin's disease', Cancer Res., 1966, 26, p. 1310. Kaplan's stage four consisted of any manifestation of disease beyond the spleen and lymph nodes and thus included, for example, involvement of the bone marrow, liver, skin, lung pleura, etc. See Henry Kaplan, 'Hodgkin's disease', J. Am. med. Ass., 1964, 190, p. 911. S A Rosenberg and H S Kaplan, 'Clinical classification of Hodgkin's disease: its importance and the influence of general signs', Nouv. Rev. Fr. Hematol., 1966, 6: 51-4.

${ }^{34}$ That is Joseph H Burchenal, James T Grace, Henry S Kaplan, Howard E Skipper, Arthur Serpick, and $\mathrm{C}$ Gordon Zubrod. Symposium held at the Westchester Country Club, Rye, New York, 13-15 September 1965. See Jack W Milder, 'Foreward', 'Obstacles to the control of Hodgkin's disease', Cancer Res., 1966, 26: 1046.

${ }^{35}$ For details, see Lukes, op. cit., note 27 above; and R J Lukes, 'Histologic features and clinical stages', J. Am. med. Ass., 1964, 190: 914-15.

${ }^{36}$ In particular, "The histologic changes do appear to be related to the anatomic extent of the disease. It seems to the authors, however, that the anatomic extent and rate of progression are related to the state of the host, which is reflected by the histologic type. It therefore appears that the anatomic extent or clinical stage is the result of the state of the host and the histologic type rather than the reverse". Robert J Lukes and James J Butler, 'The pathology and nomenclature of Hodgkin's disease', Cancer Res., 1966, 26: 1063-83, p. 1073.

${ }^{37}$ Pathologic staging followed the introduction of staging laparotomy (see above). The latter had shown the difficulty of aligning the Rye clinical stages with the Rye histopathological categories in the sense that institutions that did not undertake laparotomy were likely to assign patients to different pathological categories than those that did. Since the whole point of the staging system was to allow for inter-institutional comparisons, the rise and spread of staging laparotomy created a serious problem for the enterprise. The solution adopted at the 1971 Ann Arbor conference consisted of separating clinical staging from histopathology and creating a parallel system of staging referred to as "Pathologic Staging". John E Ultmann and Edgar M Moran, 'Diagnostic evaluation and clinical staging in Hodgkin's disease: usefulness and problems of the Ann Arbor staging classification in primary staging and staging in relapse', National Cancer Institute Monograph, 1973, 36: 333-45, on p. 333. 


\section{Peter Keating and Alberto Cambrosio}

variable speed with which the disease progressed expressed biological differences between patients, not differences between disease entities. ${ }^{38}$ This was, in fact, exactly how Lukes and Butler had described the histologic "types" of Hodgkin's disease when they noted that "[t]he histologic findings are regarded as reflections of differences in the state of host responsiveness". ${ }^{39}$ In other words, Lukes' histologic categories could be termed prognostic in the sense that they represented different degrees of progression and variations in the expression of the same disease. They were therefore not diagnostic in the traditional sense: they did not isolate distinct disease entities. This new biomedical configuration of prognosis and diagnosis had also produced a subtle shift in disease definition.

\section{From Treated History to Natural History and Back Again}

The shift from clinical pictures and classes to stages corresponded with a shift in the conception of the natural history of Hodgkin's and in those who wrote that history. Formerly the purview of pathologists like Lukes, the natural history of Hodgkin's became caught up in its treated history in the post-war era, as radiotherapists gained an unparalleled view of the pathological process. More precisely, given that patients generally presented with disseminated disease, pathologists had surmised that, like the leukaemias, Hodgkin's arose as a multifocal disease. Widespread radiation therapy, however, transformed that view when therapy and staging offered significant new evidence that Hodgkin's emerged from a single point. ${ }^{40}$ As the foremost radiotherapists in the United States, the Stanford team of Saul Rosenberg and Henry Kaplan, noted in a landmark study of therapeutic failures presented at the Rye conference, in cases where the disease returned following therapy the site of the return was far from random:

$85 \%$ of the patients in this study in whom high dose irradiation was followed by any subsequent manifestation of disease, demonstrated disease, unrecognized in the initial evaluation, in areas immediately adjacent to the treated fields. ${ }^{41}$

The therapeutic consequences of the model according to which the disease spread orderly through the lymph nodes, ${ }^{42}$ were clear: "in the initial approach to patients with Hodgkin's disease it is reasonable to treat not only the known areas of involvement, but the areas immediately adjacent to the known disease". ${ }^{43}$ Known as "extended field" therapy, the technique soon became standard in the United States and Europe "despite the difficulties

38 "We are all aware that the disease proceeds at a different tempo in different patients depending, I think, upon genetic factors and the biologic environment in which these operate". Antonio Rottino, 'Discussion on: the clinical picture of Hodgkin's disease', Cancer Res., 1966, 26: 1061-2, p. 1061.

${ }^{39}$ Lukes and Butler, op. cit., note 36 above, p. 1063. More precisely, the numerous histologic expressions found in Hodgkin's disease appear to represent manifestations of differences in the host's response rather than a mixed lymphoma as suggested by Lumb and Berman. G Lumb, Tumours of the lymphoid tissue, Edinburgh, E \& S Livingston, 1954; L Berman, 'Malignant lymphomas-Their classification and their relation to leukemia', Blood, 1953, 8: 195-210.
${ }^{40}$ For this problem, see Jackson and Parker, op. cit., note 15 above; Gilbert, op. cit., note 19 above; and Peters, op. cit., note 24 above.

${ }^{41}$ S A Rosenberg and H S Kaplan, 'Evidence for an orderly progression in the spread of Hodgkin's disease', Cancer Res., 1966, 26: 1225-31, p. 1229.

${ }^{42}$ This did not explain how, for example, one could find Reed-Sternberg cells in the peripheral blood. See B A Bouroncle, 'Sternberg-Reed cells in the peripheral blood of patients with Hodgkin's disease', Blood, 1966, 27: 544-56.

${ }^{43}$ Rosenberg and Kaplan, op. cit., note 41 above, p. 1229. 


\section{Diagnosis, Prognosis and Classification of Lymphomas}

associated with execution". ${ }^{44}$ In the course of the 1950 s and 1960 s, therefore, an essentially clinical-prognostic system-staging-transformed understanding of the pathophysiology of Hodgkin's by ordering treatment results in a reasonably consistent and coherent fashion. In turn, the renewed understanding of the pathological process transformed therapeutic rationale and modalities.

Even though subsequent clinical statistics generally confirmed Kaplan and Rosenberg's theory of progression, a variety of stances vis-à-vis the theory itself were possible. Peters, for example, although she adhered to the therapeutic prescriptions of Kaplan and Rosenberg, did not endorse a simple monofocal theory of the origin of the disease. Instead, Peters contended that there were two types: unifocal and multifocal ${ }^{45}$ Basing her position on the clinical observation that most of the patients presenting with early disease were young and presented with a local or regional swelling, she further observed that shortterm survivors consisted mainly of elderly patients presenting with constitutional symptoms which suggested a multifocal origin. ${ }^{46}$ Unlike Peters, Joseph Sokal of the Roswell Park Cancer Institute in Buffalo accepted neither the pathology nor the therapeutic consequences. At a general session on radiotherapy following the Rosenberg and Kaplan presentation at the Rye conference, Sokal accused the two of exaggeration:

Dr. Rosenberg implied that orderly progression is observed in $80 \%$ of patients with Hodgkin's; others might say $20 \%$. Orderly progression of itself does not prove the case for irradiation of apparently uninvolved areas. The hazard of not irradiating an area which may be minimally involved has been exaggerated by Dr. Kaplan. These areas can usually receive tumoricidal doses just as effectively at a later date. ${ }^{47}$

Both Rosenberg and Kaplan admitted during the session that their study did not prove that Hodgkin's had a unifocal centre but rather that it lent the notion "a high probability".

Not only did this novel conjoining of prognosis and diagnosis generate new hypotheses concerning the pathology of Hodgkin's, but it allowed the study of the pathology to be pursued within the framework of clinical research. In fact, Kaplan and Rosenberg had already initiated a clinical trial to examine the process, the preliminary results of which they presented at Rye. ${ }^{48}$ As the trial had been underway for only three years, comparisons could not be made. However, two diagnostic innovations of the 1960s had expanded exploration of the biology of the disease beyond the original biopsy and the physical examination to include both a lymphangiogram (which allowed visualization of the retroperitoneal lymph nodes), and the staging laparotomy (a surgical biopsy of multiple organ sites) ${ }^{49}$ While we

\footnotetext{
${ }^{44}$ As Tubiana explains, radiation therapy "requires great skill" and "remains technically difficult", thus the "unfavorable results of radiation therapy and the high toxicity initially associated with radiation therapy in some centers [in Europe, in the 1960s] were due in part to inadequate equipment but mainly to the insufficient experience of the team". Tubiana, op. cit., note 20 above, p. 27.

${ }^{45}$ In a retrospective review of the treatment of Hodgkin's, Rosenberg claims that Peters adopted a "concept of unicentric origin and orderly progression and treated patients with extended fields of radiation". Rosenberg, op. cit., note 23 above, p. 51.
}

\footnotetext{
${ }^{46} \mathrm{M}$ Vera Peters, 'Prophylactic treatment of adjacent areas in Hodgkin's disease', Cancer Res., 1966, 26: 1232-43, p. 1240.

${ }^{47} \mathrm{C}$ Gordon Zubrod, 'Summary of informal discussion on: Radiation therapy', Cancer Res., 1966, 26: $1264-7$, p. 1264.

${ }^{48}$ H S Kaplan and S A Rosenberg, 'Extended-field radical radiotherapy in advanced Hodgkin's disease: short-term results of 2 randomized clinical trials', Cancer Res., 1966, 26: 1268-76.

${ }^{49}$ On these techniques, see J B Kinmonth, G W Taylor, and R K Harper, 'Lymphography: a technique for its clinical use in the lower limbs', Br. med. J., 1955, i: 940-2; B J Lee, J H Nelson,
} 


\section{Peter Keating and Alberto Cambrosio}

cannot deal with these techniques here, it should be noted that they considerably expanded the clinical data and thus the prognostic possibilities inherent in the clinical trials conducted to date. ${ }^{50}$

Histories of Hodgkin's disease vary little in their evaluation of the contributions of staging, in general, and Kaplan and Rosenberg's theory, in particular. Here is a recapitulation of what has so far been presented in a history of Hodgkin's therapy in Europe:

The irradiation of the neighbouring uninvolved lymphatic areas, as performed in Toronto by Peters was controversial. Moreover, Kaplan in 1965 had developed an irradiation technique in which all the lymphatic areas located on the same side of the diaphragm were irradiated by single anterior and posterior fields. The rationale behind this technique was based on three assumptions: (a) the disease spreads via lymphatic channels to contiguous lymph node chains and other lymphatic structures; (b) the diaphragm represents a boundary between the upper and lower torso; and (c) the progression from stage II ... to stage III . . corresponds to a marked increase in the seriousness of the disease. ${ }^{51}$

Similarly, but considerably more briefly, the Italian Hodgkin's specialist, Gianni Bonadonna, lists " 1965 Rosenberg and Kaplan: Evidence for an orderly progression in the spread" as a major turning point in his 'Chronological flow of major concepts and events influencing the evolution of the treatment of Hodgkin's disease'. ${ }^{52}$ Likewise, in a list of "major advances in Hodgkin's disease", Vincent DeVita and George Canellos single out the discovery of the contiguous, orderly progression and the related staging system for special attention:

3. Description of the mode of spread of the disease, which was contiguous, unlike other malignancies (Gilbert, Peters, and Kaplan)

4. Staging system, which was based on the data on the mode of spread, and proved to be a prototype of staging classifications for other malignancies (Kaplan and others). ${ }^{53}$

Finally, recent work continues to recognize the unequivocal importance of this breakthrough. A 1998 radiotherapy study of Hodgkin's patients begins by stating: "Advancements made in the radiotherapy of Hodgkin's disease may be attributed, by and large, to an improved understanding of its mode of progression". 54

So, what have we learned? First, the notion of clinical stages in Hodgkin's disease clearly emerged ahead of and outside biological and pathological theories of the spread of the disease. Second, the stages were grounded in clinical observation concerning the recurrence of the disease following therapy. Third, using the stages, Lukes created a histopathological classification of Hodgkin's disease that generated further prognostic information. Fourth,

and G Schwarz, 'Evaluation of lymphangiography, inferior venocavography and intervenous pyleography in the clinical staging and management of Hodgkin's disease and lymphosacoma', N. Engl. J. Med., 1964, 271: 327-37; E Glatstein et al., 'The value of laparotomy and splenectomy in the staging of Hodgkin's disease', Cancer, 1969, 24: 709-18.

${ }^{50}$ Begun in the late $1960 \mathrm{~s}$, the staging laparotomy allows for what is termed "pathological staging" as opposed to "clinical staging". Glatstein et al., ibid. As a major surgical procedure requiring complete anaesthesia, the staging laparotomy bears the risks associated with all surgery. This is particularly the case

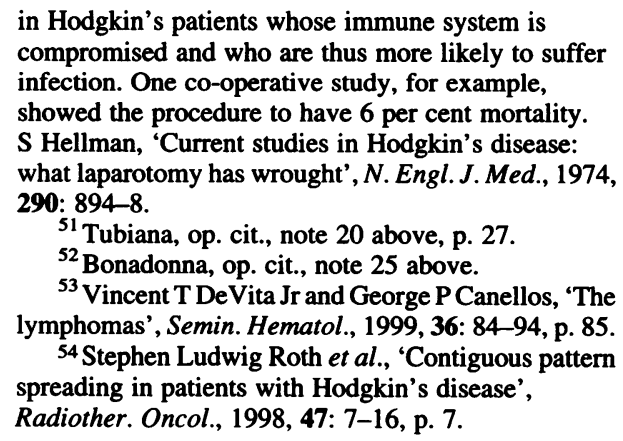

in Hodgkin's patients whose immune system is compromised and who are thus more likely to suffer infection. One co-operative study, for example, showed the procedure to have 6 per cent mortality. S Hellman, 'Current studies in Hodgkin's disease: what laparotomy has wrought', N. Engl. J.Med., 1974, 290: 894-8.

${ }^{51}$ Tubiana, op. cit., note 20 above, p. 27.

${ }^{52}$ Bonadonna, op. cit., note 25 above.

${ }^{53}$ Vincent T DeVita Jr and George P Canellos, 'The lymphomas', Semin. Hematol., 1999, 36: 84-94, p. 85.

${ }^{54}$ Stephen Ludwig Roth et al., 'Contiguous pattern spreading in patients with Hodgkin's disease', Radiother. Oncol., 1998, 47: 7-16, p. 7. 


\section{Diagnosis, Prognosis and Classification of Lymphomas}

the appearance of multiple theories of the spread of Hodgkin's did nothing to diminish the utility of Peters' stages. All clinical trials continued to use the stages as a starting point. The stages were, in other words, relatively invulnerable to changes in biology and pathology. The theories of the spread of Hodgkin's were not, of course, useless. As a recent editorial concerning the spread of Hodgkin's recognized, regardless of the exact nature of a "correct" theory, Kaplan and Rosenberg's "hypothesis" "constituted the rationale to undertake large prophylactic irradiation" and continues to have relevance today. ${ }^{55}$ The relative autonomy of the Hodgkin's staging system, first codified in Paris and Rye, was reaffirmed in subsequent reforms known as the Ann Arbor (1971) and Cotswolds (1979) reforms. ${ }^{56}$

No such elucidation occurred with the non-Hodgkin's lymphomas. Briefly, the staging system that worked so well in Hodgkin's provided relatively little prognostic information in the case of the lymphomas. Clinical researchers consequently turned to the histopathological classification for guidance. Here, however, the immunological revolution of the early 1970s undermined the biological basis of the histology leading to a series of reforms that, in the end, forced clinicians to accept a classification that made no pretence of prognosis and that was, in fact, openly hostile to such attempts.

\section{Non-Hodgkin's Lymphomas and the Confrontation of Biology and Pathology}

Until the advent of combination chemotherapy in the late 1960s, the treatment of nonHodgkin's lymphomas, like that of Hodgkin's, consisted mainly of radiation. As with Hodgkin's disease, the tumour, node, metastasis staging (TNM) was not appropriate. In the case of the lymphomas, this was in part because there is no way to determine the site of origin of the disease. Consequently, it is impossible to distinguish between the three elements of the TNM system. ${ }^{57}$ Most radiotherapists had, by then, adopted Peters' and later the Rye staging system for the NHLs, in part because they treated both Hodgkin's and the NHLs. The National Cancer Institute Radiation Branch, for example, had adopted Peters' classification in a pilot study of radiation therapy for stage three and four NHLs initiated in $1964 .^{58}$ Thus, following the acceptance of the Paris-Rye conventions for the staging of Hodgkin's disease, clinical researchers in the field of chemotherapy proposed the adoption of a similar system for the NHLs. ${ }^{59}$

\footnotetext{
${ }^{55}$ Patrice Carde and Evert M Noordijk, 'Studying spreading pattern in Hodgkin's disease: is it relevant to modern cancer treatment?', Radiother. Oncol., 1998, 47: 3-5, p. 3.

${ }^{56}$ On the Ann Arbor revisions, see for example, Ultmann and Moran, op. cit., note 37 above. For the report of the Cotswolds meeting, see A Lister et al., 'Report of a committee convened to discuss the evaluation and staging of patients with Hodgkin's disease: Cotswolds meeting', J. Clin. Oncol., 1989, 7: $1630-6$.

${ }^{57}$ For a recent overview of staging NHL, see Lena Specht, 'Staging systems and staging investigations', in Magrath (ed.), op. cit., note 10 above, pp. 533-53.

${ }^{58}$ See Ralph E Johnson, Gregory T O'Connor, and David Levin, 'Primary
}

management of advanced lymphosarcoma with radiotherapy', Cancer, 1970, 25: 787-91, p. 787. Peters' classification applied to the NHLs can be found in M V Peters, $R$ Hasselback, and T C Brown, 'The natural history of the lymphomas related to the clinical classification', in C Zarafonetis (ed.), Proceedings of the international conference of leukemialymphoma, Philadelphia, Lea \& Febiger, 1968, pp. 357-71.

${ }^{59}$ The Committee for the Study of Malignant Lymphomas of the National Cancer Institute of Milan was the first to make such a proposal. See Alberto Banfi et al., 'Proposta di classificazione et criteri terapeutici del linfosarcoma e del reticulosarcoma', Tumori, 1965, 51: 153-78. 


\section{Peter Keating and Alberto Cambrosio}

Although radiotherapists noted that survival rates were considerably superior for patients with truly localized disease, ${ }^{60}$ unlike Hodgkin's the lymphomas rarely presented themselves as localized in the lymph nodes, and patients with stage two and beyond rarely survived. ${ }^{61}$ Moreover, the spread of disease in the lymphomas did not follow the orderly pattern observed in Hodgkin's, so rendering the prophylactic radiation strategy useless. ${ }^{62}$ These observations were subsequently restated by chemotherapists in a series of studies on the pattern of spread and involvement dating back to the beginnings of combination therapy in the early 1970 s. $^{63}$

None the less, throughout the 1970s and 1980s, co-operative group trials continued to report their results in terms of stages, and investigators sought prognostic information within the stages. For example, Bartolucci, Durant and Gams found that spread of the disease beyond the lymph nodes was prognostically bad. ${ }^{64}$ Moreover, even though Rosenberg had pronounced the staging system of limited value in 1977 and despite the development of over twenty alternative systems in the 1980 s, $^{65}$ the Ann Arbor (1971) modification of the Rye system remained the most commonly used. ${ }^{66}$ Even though it provided little prognostic or therapeutic information, it did enable investigators to isolate the few cases amenable to radiation therapy (stage one) and to use "a standardized method by which to classify patients for comparison of clinical trials". ${ }^{7}$

\footnotetext{
${ }^{60}$ A Lipton and Burton J Lee, 'Prognosis of stage I lymphosarcoma and reticulum cell sarcoma', N. Engl. J. Med., 1971, 284: 230-3.

${ }^{61}$ R E Johnson, G T O'Conor, and D Levine, 'Primary management of advanced lymphosarcoma with radiotherapy', Cancer, 1970, 25: 787-91; R C Young et al., 'Advanced lymphocytic lymphoma: Randomized comparisons of chemotherapy and radiotherapy alone or in combination', Cancer Treat. Rep., 1977, 61: 1153-9; J T Chaffey et al., 'Total-body irradiation in the treatment of lymphocytic lymphoma', Cancer Treat. Rep., 1977, 61: 1149-52; S C Carabell et al., 'Results of total body irradiation in the treatment of advanced non-Hodgkin's lymphomas', Cancer, 1979, 43: 994-1000; H C Boston et al., 'Malignant lymphoma (so-called reticulum cell sarcoma) of bone', Cancer, 1974, 34: 1131-7; C C Wang and D J Fleischli, 'Primary reticulum cell sarcoma of bone. With emphasis on radiation therapy', Cancer, 1968, 22 : 994-8; J Newall and M Friedman, 'Reticulum-cell sarcoma. Part III. Prognosis', Radiology, 1970, 97: 99-102; T R Miller and J T Nicholson, 'End results in reticulum cell sarcoma of bone treated by bacterial toxin therapy alone or combined with surgery and/or radiotherapy (47 cases) or with concurrent infection (5 cases)', Cancer, 1971, 27: 524-48.

${ }^{62}$ See, for example, the cases collected and reviewed in Hanne Sand Hansen, 'Reticulum cell sarcoma treated by radiotherapy. Significance of clinical features upon the prognosis', Acta Radiol. Ther. Phys. Biol., 1969, 8: 439-58; Urpo Tikka and Kai Malmio, 'Clinical and radiotherapeutic aspects of reticulum cell sarcoma', Acta Radiol.Ther. Phys. Biol., 1969, 8: 459-70; Leonard R Prosnitz et al., 'The clinical course of Hodgkin's disease and other
}

malignant lymphomas treated with radical radiation therapy', Am. J. Roentgenol., 1969, 105: 618-28.

${ }^{63}$ D R Goffinet et al., 'Clinical and surgical (laparotomy) evaluation of patients with nonHodgkin's lymphomas', Cancer Treat. Rep., 1977, 61: 981-92; B A Chabner et al., 'Sequential nonsurgical and surgical staging of non-Hodgkin's lymphoma', Cancer, 1978, 42: 922-5; J D Bitran et al., 'Non-Hodgkin's lymphoma, poorly differentiated lymphocytic and mixed cell types. Results of sequential staging procedures, response to therapy, and survival of 100 patients', Cancer, 1978, 42: 88-95; T Anderson et al., 'Malignant lymphoma: I. The histology and staging of 473 patients at the National Cancer Institute', Cancer, 1982, 50: 2699-707; The Non-Hodgkin's Lymphoma Pathologic Classification Project, 'National Cancer Institute sponsored study of classifications of non-Hodgkin's lymphomas: summary and description of a working formulation for clinical usage', Cancer, 1982, 49: 2112-35.

${ }^{64}$ A Bartolucci, J R Durant, and R A Gams, 'Prognostic factors in non-Hodgkin's lymphomas: a multivariate analysis of over 300 cases', ASCO, 1977, 18, p. 304; and N I Nissen et al., 'Overview of four clinical studies of chemotherapy for stage III and stage IV non-Hodgkin's lymphomas by the Cancer and Leukemia Group B', Cancer Treat. Rep., 1977, 61: 1097-107.

${ }^{65}$ The various systems are described in Specht, op. cit., note 57 above.

${ }^{66} \mathrm{~J}$ A Moormeier, S F Williams, and H M Golomb, 'The staging of non-Hodgkin's lymphomas', Semin. Oncol., 1990, 17: 43-50, p. 43.

${ }^{67}$ Ibid. 


\section{Diagnosis, Prognosis and Classification of Lymphomas}

Given the drawbacks, and despite the continued use of clinical staging, clinician researchers came to see the management of the NHLs according to histology as far more satisfactory from the point of view of prognosis. So, when the NCI co-operative clinical trials groups began chemotherapy trials with the NHLs at the end of the 1950s, they recruited Robert Lukes to develop a pathological classification of the non-Hodgkin's lymphomas. ${ }^{68}$ To do so, Lukes drew on the work of a former colleague at the US Army Institute of Pathology, Henry Rappaport. A well-known Chicago pathologist, Rappaport had been contracted by the Army Institute in the mid-1950s to produce a tumour atlas covering tumours of the lymphatic system, including Hodgkin's disease. The Army Institute had commissioned Rappaport after rejecting as somewhat "self-righteous" a manuscript submitted on the same topic by R Philip Custer. ${ }^{69}$ Basing his classification on the vast collection maintained by the Army Institute of Pathology, Rappaport proposed a fundamental reordering of the lymphomas that added an explicit prognostic/clinical dimension to what had been mainly a diagnostic/histopathological classification. ${ }^{70}$

Rappaport's prognosis was embedded in part in a new architectural analysis of the lymph node biopsy specimens. This distinguished between lymph nodes that appeared to have enlarged follicules or nodes, and those-termed diffuse-that did not. First published in schematic form in the mid-1950s, Rappaport's classification divided the former into five cytological types, the last being Hodgkin's which, given the singularity represented by the Reed-Sternberg cells, he and his colleagues admitted did not seem to have much business being there. Based mainly on size, the designations were not simply visual. In so far as size indicated a stage of lymphocyte development, large cells represented those in the process of proliferation. Clinicians and pathologists could thus attribute to lymphomas composed mainly of large cells the properties associated with rapid growth, namely a more aggressive clinical evolution. When the system appeared ten years later in 1966 as part of the Atlas of Tumor Pathology - "one of the most influential publications in American pathology" 71 - it sold more than any other fascicle of that collection with total sales worldwide at 15,300 copies. $^{72}$

\footnotetext{
${ }^{68}$ See Peter Keating and Alberto Cambrosio, 'From screening to clinical research: the cure of leukemia and the early development of the cooperative oncology groups: 1955-1966', Bull. Hist. Med., 2002, 76: $299-334$.

${ }^{69}$ See Arthur Purdy Sout, Chairman, Subcommittee on Oncology to Henry Rappaport, Mt Sinai Hospital, Chicago, Ill., 14 April 1956, Armed Forces Institute of Pathology Archives, Correspondence, 1956-1961. As F W Stewart of the publication committee had remarked when Rappaport finally submitted his monograph, "It [Rappaport's manuscript] lacks the self-assured righteousness of the Custer monograph that we had to reject". F W Stewart to Catherine Blumberg, 30 Dec. 1959, Atlas of Tumor Pathology, 'Criticism and Critical Reviews', Box 31, Armed Forces Institute of Pathology Archives.

${ }^{70}$ See H Rappaport, W J Winter, and E B Hicks 'Follicular lymphoma. A re-evaluation of its position in the scheme of malignant lymphoma based on a survey of 253 cases', Cancer, 1956, 9: 792-821. This paper became the basis of the 1966 classification published
}

as H Rappaport, Tumors of the hematopoietic system. Atlas of tumor pathology, Section 3, Fascicle 8, Washington, DC, US Armed Forces Institute of Pathology, 1966. The ten-year delay can be largely explained by administrative problems within the Army Institute of Pathology.

${ }^{71}$ Juan Rosai to William Hartmann, 31 May 1977, 'Fascicles Editorial Advisory Committee', Correspondence, Army Institute of Pathology Archives, 1977.

${ }^{72}$ Army Institute of Pathology, Annual Report, 1972, p. 116. As the director of the Atlas of Tumor Pathology noted at the time: "As I understand it, it has always been customary to print about 5,000 to 6,000 copies of each fascicle and then when the supply runs low to reprint until 15,000 copies have been printed. In the case of Tumors of the Hematopoietic System, the market was so thirsty and the Fascicle so superb that all the copies were gone in about five months". Harlan I Firminger to Henry Rappaport, 23 May 1967, Box 31, Correspondence, Army Institute of Pathology Archives, 1961-1967. 


\section{Peter Keating and Alberto Cambrosio}

As head of the Pathology Advisory Committee of the NCI clinical cancer trial groups programme, and in the absence of a staging system for the non-Hodgkin's lymphomas, Lukes needed a "provisional classification and grouping" of the latter in order to organize patients into histopathological diagnostic groups. The 1956 version of Rappaport's system provided just such criteria with the added prognostic bonus. Noting that the system would be "subject to verification on the basis of future experience", Lukes outlined the possible pitfalls of such a bootstrapping operation. The serial correction proposed by the Pathology Advisory Committee-start with simple categories and see what turns up_presupposed that the large categories themselves could be easily filled. As Lukes demonstrated, however, pathologists could be consistently confounded in the diagnosis of lymphomas, notably in confusing the benign with the malignant, the most important prognostic categories of all. Partly because of considerable visual overlap between entities, histopathologic diagnosis was further complicated by the fact that many of the preparations involved manual techniques. In some instances, the only way to ensure consistency of preparation was to institutionalize bias: Lukes' group, for example, employed "one specially trained technician to prepare all the histologic sections". ${ }^{73}$ Moreover, a team of three pathologists headed by Lukes studied all histology sections prepared for the Southeastern group at the Army Institute of Pathology, reaching diagnosis by consensus. This careful pathology was only a beginning. Thus, Lukes believed that, ultimately, it would be "essential for the pathologists of each study group to collaborate in a comparative study of histologic case material in an attempt to achieve uniform criteria for diagnosis and classification of the lymphomas". ${ }^{74}$

The large-scale clinical trials for non-Hodgkin's lymphomas that emerged at about the time of the Rye conference further bolstered the value of histologic management and Rappaport's classification. Following the formation of the task forces by the NCI, and in order to ensure uniformity of diagnosis in the lymphomas and thus to ensure comparability of treatment results, the Lymphoma Task Force set up a pathology panel run this time by Rappaport himself. Reporting to the Lymphoma Task Force in 1967, Rappaport noted that the pathology panel served "as a critical reference for the diagnosis and classification of pathologic specimens from patients with lymphomas entered in co-operative group chemotherapy protocols". ${ }^{75}$ As head of the panel, Rappaport was in a position to mandate his prognostic-histopathologic system for the lymphomas as a progressively widening standard. The fact that the late 1960s had also seen the introduction of a "standard" chemotherapy treatment (CHOP) meant that a growing number of phase two and phase three protocols were needed to extend the original findings (phase one) and compare alternatives to the standard (phase three). From 1970 to 1977, the total number of lymphoma chemotherapy protocols (including both Hodgkin's disease and NHL) doubled from fifteen to thirty. Between 1967 and 1976, the panel reviewed 5,375 cases, and so collected almost as many cases in nine years as the US Army Institute of Pathology had in thirty

\footnotetext{
${ }^{73}$ Robert $\mathrm{J}$ Lukes, 'Investigations in malignant lymphomas', in Conference on experimental clinical cancer chemotherapy, National Cancer Institute Monograph No. 3, Washington, U.S. Government Printing Office, 1960, pp. 193-312, on p. 199.

${ }^{74}$ Ibid., p. 200.
}

\footnotetext{
${ }^{75}$ Minutes of the Lymphoma Task Force, 16 June 1967, p. 1. NCI Archives. AR-6802-001829. The Panel had held its first organizational meeting in March. The minutes of that meeting are included in the appendix to the present document. See National Cancer Institute, Lymphoma Task Force, Pathology Panel, Bethesda, Maryland, 9-10 March 1967.
} 


\section{Diagnosis, Prognosis and Classification of Lymphomas}

years. ${ }^{76}$ The fact that by the mid-1970s the panel reviewed and classified around 1,000 slides a year according to the Rappaport system, gave them unparalleled expertise and Rappaport's system unparalleled authority in the field of the non-Hodgkin's lymphomas. ${ }^{77}$

Buoyed by its recognized prognostic significance and status within the American clinical trial system, Rappaport's system thus became the classification for "pathological staging" for clinical trials in the United States. ${ }^{78}$ As testimony to its widespread use, when reviewing the methods and strategies of co-operative clinical trials in the late 1970s, Franco Muggia and his colleagues at the Southwest Oncology Group ${ }^{79}$ concluded that one of the characteristics of the 1970s had been the "individualization of protocols for favourable and unfavourable histologies according to the Rappaport classification". 80 Yet, despite its acceptance, problems plagued the Rappaport system throughout the 1970s. The use of histology rather than staging to manage patients brought clinicians treating NHLs into closer contact with "biological" reality than clinicians who treated Hodgkin's. Prognostic stages could be used within a therapeutic strategy regardless of the underlying biology of the spread of Hodgkin's; with NHLs, however, each histologic entity referred, in principle, to a different underlying biological entity: the cell of origin. If the biology changed, so did the pathology. Thus, when the biology of the immune system changed during the 1970s with the rise of cellular immunology and the constitution of new entities known as T and B cells, it had a more immediate and direct impact on the management of NHLs than on the management of Hodgkin's.

In the early 1970 s, a series of alternative classifications emerged that claimed to make better sense biologically of the different forms of lymphoma even though they did not necessarily improve management. Under pressure from these "immunological" analyses, the cells known to pathologists as histiocytes, for example, began to appear in quotation marks signifying their uncertain status. The most damaging work appeared in the early 1980s when large-scale studies showed that the histiocytes were, in fact, what immunologists had been calling B-cells for some ten years. ${ }^{81}$ Some users of the Rappaport system

\footnotetext{
${ }^{76}$ Between 1925 and 1954, the American Lymph Node Registry, transferred to the Army Museum (later Institute) of Pathology during the 1930 s, collected 5,500 cases. Annual Report, Armed Forces Institute of Pathology, 1954, p. 19.

${ }^{77}$ The Center also received specimens from the Hodgkin's disease radiotherapy group and "Personal referrals from many sources". See 'Clinical cooperative group program: Clinical trials review', Memorandum from the Associate Branch Chief, Clinical Investigations Branch (Edwin Jacobs) to Dr John Macdonald, Associate Director, Cancer Therapy Evaluation Program, 28 Nov. 1978, p. 48, NCI Archives.

${ }^{78}$ See for example, M J Lotz et al., 'Pathological staging of 100 consecutive untreated patients with nonHodgkin's lymphomas: extramedullary sites of disease', Cancer, 1976, 37: 266-70.

${ }^{79} \mathrm{~A}$ history of the group entitled 'The history and evolution of the Southwest Oncology Group' can be found at their website at www.swog.org.

${ }^{80} \mathrm{~F}$ M Muggia, H L Davis, and M Rozencweig, 'Current cooperative clinical trials in the non-
}

Hodgkin's lymphomas', Cancer Treat. Rep., 1977, 61 : 1191-7.

${ }^{81}$ See for example, R J Lukes et al., 'Immunologic approach to non-Hodgkin lymphomas and related leukemias. Analysis of the results of multiparameter studies of 425 cases', Semin. Hematol., 1978, 15: 322-51, and R J Lukes et al., 'A morphologic and immunologic surface marker study of 299 cases of non-Hodgkin lymphomas and related leukemias', $A m$. J. Pathol., 1978, 90: 461-85. Ironically, Rappaport's classification had originally been resisted on similar grounds of mis-identification of cells. Some pathologists felt, for example, that Rappaport had failed to show, on morphological grounds, that the histiocyte existed where indicated on the slides. As one reviewer of Rappaport's contribution to the Atlas of Tumor Pathology put it, "One of the features of Dr Rappaport's classifications and nomenclature is that, by and large, he has substituted the word 'histiocyte' for 'reticulum cell'. He does this on the ground that the histiocyte is a differentiated cell distinguishable from undifferentiated reticulum cells by the metalophil properties [silver-staining] as indicated by Marshall. 


\section{Peter Keating and Alberto Cambrosio}

saw no reason to abandon this clinically useful framework. Lead researchers in lymphoma chemotherapy at the NCI, for example, cheerfully admitted that though the category was "scientifically incorrect", it was still "clinically relevant" ${ }^{82}$ For their part, Rappaport and his colleagues claimed in a subsequent study comparing the immunological and histological systems that "diffuse histiocytic lymphomas" were better prognosticators than the corresponding immunological categories. ${ }^{83}$ Herein lay the dilemma. In the lymphomas, prognosis depended less on disease extent (clinical staging) than histopathologic subtype (pathologic staging). Indeed, investigators typically staged according to histology and distinguished between "good" histologies (nodular) and "bad" histologies (diffuse). ${ }^{84}$ The problem with this prognosis was the status of the entities whose future the Rappaport system purported to describe: from a biological perspective, as we have just seen, they no longer existed.

Rappaport's system was further compromised in the late 1970s by user complaints suggesting that without the centralized review offered by the expert pathologists serving on Rappaport's panel, use of Rappaport's system in the co-operative groups gave mixed results. A study by the Southwest Oncology Group showed that the degree of agreement (on both type and subtype) between the members of the Lymphoma Pathology Review Panel and hospital pathologists was a mere 58 per cent. ${ }^{85} \mathrm{~A}$ study conducted by the Eastern Cooperative Oncology Group gave similar results: in a series of 535 cases, despite 96 per cent agreement on the diagnosis of NHL, when it came to the crux of Rappaport's systemcell type and pattern-agreement fell to 79 per cent. ${ }^{86}$ The Southeastern Cancer Study Group found even less accord. ${ }^{87}$

\begin{abstract}
Yet nowhere in the fascicle do we find descriptions or illustrations of applications of the metalophil method to support the designation of certain cells as histiocytes or of histiocytic derivation". Clyde J Dawe to 'Review' 22 Jan. 1960, Atlas of Tumor Pathology, 'Criticism and Critical Reviews', Box 31, Armed Forces Institute of Pathology Archives.

${ }^{82}$ They proposed, in particular, that further morphological analysis would allow clinicians to subdivide the category into two different groups with differing prognoses and that having reworked their own data, proposed to others that "Morphologic subclassification of diffuse 'histiocytic' lymphoma may be useful in predicting response to chemotherapy and survival". J A Strauchen et al., "Clinical relevance of the histopathological subclassification of diffuse "histiocytic" lymphoma', N. Engl.J. Med., 1978, 299: $1382-7$, p. 1382 . Indeed, as explicitly stated by an international panel of experts set up in the early 1980 s by the NCI to study the problem, The Non-Hodgkin's Lymphoma Classification project: "One of the most controversial aspects of the Rappaport classification concerns the group of tumors included within 'diffuse histiocytic lymphoma'. The term 'histiocytic' is now known to be, in some instances, scientifically incorrect. The large cells found in these neoplasms are in most cases derived from lymphocytes, while lymphomas of true histiocytic nature are rare." The Non-Hodgkin's
\end{abstract}

Lymphoma Pathologic Classification Project, op. cit., note 63 above, p. 2120.

${ }^{83}$ B N Nathwani et al., "The clinical significance of the morphological subdivision of diffuse "histiocytic" lymphoma: a study of 162 patients treated by the Southwest Oncology Group', Blood, 1982, 60: 106874, p. 1068.

${ }^{84}$ As summarized in a review of co-operative group trials prepared for the Division of Cancer Treatment: "Prospective trials from all cooperative groups have confirmed the better responsiveness and superior survival of the lymphomas with a nodular pattern (good risk or favourable histologies) versus those of the diffuse type (poor risk or unfavorable)." Charles A Coltman et al., 'Lymphoma', in Barth Hoogstraten (ed.), Cancer research: impact of the cooperative groups, New York, Masson, 1980 , pp. $39-84$, on p. 68.

${ }^{85} \mathrm{~S}$ E Jones et al., 'Histopathologic review of lymphoma cases from the Southwest Oncology Group', Cancer, 1977, 39: 1071-6.

${ }^{86}$ E Ezdinli et al., 'Eastern Cooperative Group experience with the Rappaport classification of nonHodgkin's lymphoma', Cancer, 1979, 43: 544-50.

${ }^{87}$ Using an outside referee to review 406 cases diagnosed by local pathologists, they found only 48 per cent agreement. These unpublished findings were reported in Coltman, op. cit., note 84 above, p. 61 . 


\section{Diagnosis, Prognosis and Classification of Lymphomas}

The development of immunology-based classifications engendered yet another problem that went beyond their apparent lack of prognostic content: were the classifications mutually compatible? An early study carried out by the European Lymphoma Club in the mid-1970s showed, paradoxically, that although the classifications were comparable, it was mainly because pathologists had equal difficulty in reproducing them. ${ }^{88}$ According to the study protocol, Club members classified fifty cases of lymphoma according to each of the three major classification schemes then available (Rappaport, Lukes-Collins and Kiel). Three independent observers then reclassified the same cases. The degree of agreement between the two groups of classifiers barely went beyond random (50 per cent) in the case of the Rappaport classification and reached an unimpressive 60 per cent in the case of the Kiel classification. $^{89}$

Following a series of conferences organized to iron out the differences between classifications, the WHO attempted to translate between systems. Rappaport had organized the first meeting entitled 'Workshop on Classification of Non-Hodgkin's Lymphomas' in Chicago in June 1973. The major protagonists came together the next year at the first international conference on lymphoma classification held in London. Optimism ran high as Henry Kaplan wrote in the introduction to the published proceedings:

It may confidently be predicted that pathologists will soon acquire an exciting new armamentarium of differential tests based on surface membrane receptors and other distinctive cytochemical and immunological properties of these cells and that histopathological classifications firmly rooted in these fundamental biological attributes will emerge. ${ }^{90}$

In the meantime, however, what did happen was the generally considered "Florence fiasco": the International Cancer Conference held in Tuscany in 1974, in the course of which irreconcilable differences became evident. Lack of consistent clinical data and treatment programmes rendered the basis for comparison subject to further controversy. So Kaplan convened yet another conference (Virginia, 1975) funded by the American National Cancer Institute. ${ }^{91}$ By invitation only, the conference was closed to outsiders in an attempt to keep the heat down. The meeting achieved no consensus. ${ }^{92}$ In order to overcome the clinical inconsistencies, therefore, the NCI had first to generate common clinical data using previously untreated patients. The NCI thus decided to organize its own series of cases especially for the purpose of comparing the classification systems. Four institutionsthree American and one European - were chosen to provide the cases for review. ${ }^{93}$

The results of the showdown were discussed at conferences held at Stanford in 1979-80, and the participants agreed that no fundamental differences had surfaced with regards to

\footnotetext{
${ }^{88}$ The Club was created by Karl Lennert in 1973 as a vehicle for the Kiel classification.

${ }^{89} \mathrm{~K}$ Lennert and $\mathrm{H}$ Stein, 'Personal points of view on the Kiel classification', in G Mathé and M Tubiana (eds), Lymphoid neoplasms I: classification, categorization and natural history, Berlin, Springer, 1978 , pp. 31-7, on pp. 35-6.

${ }^{90}$ H S Kaplan, 'Introduction', Br. J. Cancer, Supplement 2, 1975, 31: vii-viii. Quoted in CW Berard and R E Hutchison, 'The problem of classifying lymphomas: an orderly prescription for progress', Ann. Oncol., Supplement 2, 1997, 8: S3-S9, p. S4.
}

\footnotetext{
${ }^{91}$ Entitled the 'Invitational Workshop for the Planning of Retrospective and Prospective Studies to Delineate Optimal Classification of the Non-Hodgkin's Lymphomas', the meeting was held in Warrenton, Virginia, 4-5 Sept. 1975. See G Mathé, 'Workshop for the classification of non-Hodgkin's lymphoma', Biomedicine, 1975, 22: 466-7.

92 Ibid.

${ }^{93}$ The institutions were: Istituto Nazionali Tumori, Milan, Italy; University of Minnesota Hospitals, Minneapolis, Minnesota; Tufts-New England Medical Center, Boston, Massachussetts; Stanford University Medical Center, Stanford, California.
} 


\section{Peter Keating and Alberto Cambrosio}

reproducibility. As to the prognostic value of the systems, investigators found that while none stood out as particularly good, none stood out as particularly poor. ${ }^{94}$ In the absence of clinical features distinguishing the systems, then, the investigators developed a "Working Formulation" (WF). Drawing histologic terminology from the Rappaport and LukesCollins classifications, the group offered the formulation not as a new classification, "but as a means of translation among all systems". 95 Published in 1982, the WF went on to become the classification of choice in North America. A 1988 study of pathologists showed that over 97 per cent used the WF whereas only 5 per cent were "familiar" with the competing ("European") Kiel system. Intended primarily for clinical use, the WF had a morphologic base (to please the pathologists) with a prognostic superstructure (to please the clinicians). Borrowed from the Kiel system and based "primarily upon differences in survival", 96 the latter included three categories: high grade, intermediate grade and low grade. ${ }^{97}$ The grading system and the Working Formulation henceforth replaced the pathological staging adopted at Ann Arbor in 1971, although the term Ann Arbor continued to be used to signify both the clinical staging and the new WF pathological staging. ${ }^{98}$

Not all the experts were pleased with the WF. Unlike the Hodgkin's pathological staging, the different histological categories in NHLs referred to different entities, and not to different stages in the development of a single entity. By combining entities within a prognostic-graded-superstructure, the WF created a tension between clinical considerations and biology that had been absent in the case of Hodgkin's disease. The German pathologist (and champion of the Kiel classification) Karl Lennert, for example, offered two reservations that were ultimately to lead to the abandonment of the Formulation: "Firstly, within this Formulation lymphoma entities which are biologically closely related are separated and entities biologically unrelated are grouped together. Secondly, all considerations regarding immunologic identities of lymphomas have been excluded". ${ }^{99}$ Lukes concurred. ${ }^{100}$ None the less, even though biology and immunology had not been included, Rappaport noted that they had not been precluded, adding, somewhat demurely, that they could be "readily added when future research establishes their clinical value above and beyond that of the histologic classification". Rappaport, moreover, pointed out with a certain sense of vindication that "the clinical relevance of pattern was recognized and the terms 'follicular' and 'diffuse' were made part of the new formulation". ${ }^{101}$

However, the WF ultimately satisfied neither the pathologists nor the clinicians. From the clinical point of view, the grading system was only partly successful. By the early 1990s, clinicians classified the intermediate and high-grade lymphomas together under the rubric of "aggressive lymphomas", as the distinction between intermediate and high melted away.

\footnotetext{
${ }^{94}$ The Non-Hodgkin's Lymphoma Pathologic Classification Project, op. cit., note 63 above, p. 2119.

${ }^{95}$ Ibid., p. 2121.

${ }^{96}$ The Kiel "grades" can be found in K Lennert et al., 'The histopathology of malignant lymphoma', Br. J. Haematol., supplement, 1975, 31: 193-203.

${ }^{97}$ The Non-Hodgkin's Lymphoma Pathologic Classification Project, op. cit., note 63 above, p. 2122. According to NCI researchers, in clinical protocols only the categories "high grade" and "low grade" were used. See Albert J Fornace Jr and Elaine S Jaffe,
}


Wiernik, George P Canellos, Robert A Kyle, and Charles A Schiffer (eds), Neoplastic diseases of the blood, New York, Churchill Livingstone, 1985, vol. 2, pp.707-36, on p. 712 .

${ }^{98}$ See for example, Moormeier, Williams, and Golomb, op. cit., note 66 above, p. 44.

${ }^{99}$ Karl Lennert, 'Commentary on working formulation of non-Hodgkin's lymphomas', Cancer, 1982, 49, p. 2133.

${ }^{100}$ Ibid., p. 2134.

${ }^{101}$ Ibid. 


\section{Diagnosis, Prognosis and Classification of Lymphomas}

In fact, the two categories offered such a variety of outcomes that clinicians soon began to look for other means of predicting results. Since a return to the Ann Arbor staging system alone had little to offer in the way of prognosis, and since the WF grades were compromised by the fact that there were now a plethora of national histopathological systems that allowed one to grade a NHL, an international consortium of clinical trial groups set out at the beginning of the 1990s to produce what became known as the International Prognostic Index (IPI). Involving more than sixteen institutions worldwide, including eleven American and European co-operative oncology groups, the consortium assembled and examined an enormous sample of over 3,000 intermediate and high-grade lymphoma patients treated with chemotherapy between 1982 and 1987. Assessing the patients according to a variety of factors such as age, Ann Arbor stage and such biological markers as blood enzymes, they created an Index that when correlated with five-year survival rates divided the patient population into four distinct groups with different survival rates. ${ }^{102}$ In other words, regardless of the different histopathological designations offered by the competing classification systems, the IPI predicted outcome based on "clinical" as opposed to "pathological" status. Subsequently validated in a number of fora and extended to advanced Hodgkin's disease, ${ }^{103}$ the IPI separated the problems attendant upon identifying different species of disease from the clinical demands of patient management and prognosis. ${ }^{104}$

Equally as dissatisfied with the WF, a number of pathologists known as the International Lymphoma Study Group also came together in the early 1990s to create a new classification of the NHLs, the REAL classification. ${ }^{105}$ The REAL responded to the criticisms of pathologists like Lennert and Lukes in that it eschewed prognostic indications in favour of the simple description of the entities involved and incorporated the newer cytogenetic and immunological descriptions of the immune cells. When presented to a group of lymphoma specialists not involved in the REAL initiative at a meeting held at the NCI, however, some participants-Rosenberg, for example-felt that the new system suffered significant shortcomings from a patient-management point of view. ${ }^{106}$ These objections were overcome

\footnotetext{
${ }^{102}$ The International Non-Hodgkin's Lymphoma Prognostic Factors Project, 'A predictive model for aggressive non-Hodgkin's lymphoma', N. Engl. J.

Med., 1993, 329: 987-94. The search continues for improved biological markers. See U Axdorph et al., 'Biological markers may add to prediction of outcome achieved by the International Prognostic Score in Hodgkin's disease', Ann. Oncol., 2000, 11: 1405-11.

${ }^{103}$ See C Gisselbrecht and C Ferme, 'Prognostic factors in advanced Hodgkin's disease: problems and pitfalls. Towards an international prognostic index', Leukemia Lymphoma, supplement 1, 1995, 15: 23-4; and Dirk Hasenclever and Volker Diehl, and the International Prognostic Factors Project on Advanced Hodgkin's Disease, 'A prognostic score for advanced Hodgkin's disease', N. Engl.J. Med., 1998, 339: 1506-14.

${ }^{104} \mathrm{M}$ A Shipp, 'Can we improve upon the International Index?', Ann. Oncol., supplement 1, 1997, 8: 43-7. C Stelitano et al., 'Validation of the International Prognostic Index in working formulation group A low-grade non-Hodgkin's lymphoma:
}

retrospective analysis of 137 patients from the Gruppo Italiano per lo Studio dei Linfomi registry',

Haematologica, 2000, 85: 154-9; G Rossi et al., 'The international prognostic index can be used as a guide to treatment decisions regarding patients with human immunodeficiency virus-related systemic non-

Hodgkin lymphoma', Cancer, 1999, 86: 2391-7, and C S Chim et al., 'CEOP treatment results and validity of the International Prognostic Index in Chinese patients with aggressive non-Hodgkin's lymphoma', Hematol. Oncol., 1998, 16: 117-23.

${ }^{105}$ Peter Keating and Alberto Cambrosio, " "Real compared to what?" Diagnosing leukemias and lymphomas', in Margaret Lock, Allan Young, and Alberto Cambrosio (eds), Living and working with the new medical technologies: intersections of inquiry, Cambridge University Press, 2000, pp. 103-34.

${ }^{106}$ Professor T A Lister (Personal communication). For Rosenberg's criticisms, see Saul A Rosenberg, 'Classification of the lymphoid neoplasms', Blood, 1994, 84: 1359-60. 


\section{Peter Keating and Alberto Cambrosio}

when clinicians and pathologists embarked upon the International Non-Hodgkin's Classification project set up to articulate the classification scheme with clinical concerns. ${ }^{107}$ The REAL had first been published in 1994. In 1997 a marginally modified version was adopted by the World Health Organization as its official classification. The WHO Clinical Advisory Committee noted in its report that the key issue was "to discriminate between disease entities and prognostic factors" (emphasis added). ${ }^{108}$ The alliance between prognosis and diagnosis created by Rappaport had come to be viewed more as a problem than a solution.

\section{Conclusion}

We have seen that with the rise of clinical research and clinical cancer trials, and the subsequent transformation of natural histories into treated histories, prognosis has emerged as a going concern for clinical researchers conducting clinical trials. Here, the emphasis was not on prognosis as advice one would give to a patient as was the case prior to the Second World War, but as a measure of therapeutic efficacy and as an indicator of the biological reactivity of the different species and subspecies of a particular class of entities to a therapeutic regime. By focusing on populations rather than on individuals, prognosis and prognostic information acquired as much a research value as a clinical value and, in consequence, created a class of consumer that was not restricted to the ill: the clinical researcher. In other words, as suggested at the beginning of this paper, the post-war rise of biomedicine resulted in a new configuration of medical practices. Formerly tied to the doctor-patient relationship, prognosis, now the object of widespread clinical trials and clinical research, has acquired a new epistemic and institutional meaning as a research device. At the same time, in the field of the lymphomas, in keeping with the tendency to analyse morbid entities and processes in biological terms, pathologists have sought to extract "natural history" from "treated history" by disentangling diagnosis and prognosis.

This process was contingent in nature. Whereas radiotherapists transformed the natural history of Hodgkin's disease and led investigations in the biology of its spread, chemotherapists had relatively less impact on the understanding of the lymphomas. Change here originated at the biological pole of the biomedical spectrum, when understanding of the immune system was profoundly changed in the late 1960s and early 1970s. As we have shown elsewhere, however, these changes in themselves were partly prompted by investigations in pathology. ${ }^{109}$ Clinical pathologists and chemotherapists subsequently followed suit in the 1980s, devising clinical trials around the new biomedical entities known as $\mathrm{T}$ cells and B cells. The advantage of the comparison between Hodgkin's and the NHLs here is thus clear. The relative success of the Rye-Ann Arbor staging system in the case of Hodgkin's

\footnotetext{
${ }^{107}$ See The Non-Hodgkin's Lymphoma Classification Project, 'A clinical evaluation of the International Lymphoma Study Group classification of non-Hodgkin's lymphoma', Blood, 1997, 89: 3909-18.

${ }^{108}$ N L Harris et al., 'The World Health Organization classification of neoplastic diseases of the hematopoietic and lymphoid tissues. Report of the Clinical Advisory Committee, Airlie House, Virginia, November, 1997', Ann. Oncol., 1999, 10: 1419-32, p. 1421. N L Harris et al., 'Lymphoma
}

\footnotetext{
classification-from controversy to consensus: The R.E.A.L. and WHO classification of lymphoid neoplasms', Ann. Oncol., supplement 1, 2000, 11: 3-10.

${ }^{109}$ See Peter Keating and Alberto Cambrosio, 'Transplantation, tumor or differentiation antigens? The view from biology and the view from pathology', American Association for the History of Medicine, 73rd Annual Meeting, Bethesda, Maryland, 18-21 May 2000.
} 
Diagnosis, Prognosis and Classification of Lymphomas

disease can be misleading for an understanding of the role of prognosis in modern biomedicine. More than a clinical method for predicting therapeutic outcomes, prognosis now deals with uncertain outcomes in the larger field of clinical research. As we have seen with the NHLs, when prognostic information is drawn from natural history, the exploration of prognosis simultaneously raises two questions: what will happen to the patient and what is the specific disease entity that we are treating? Changes in biology necessarily change the description of disease entities and thus impact much more directly upon patient prognosis. In this sense, biomedicine is a two-way street. 